\author{
dr Anna ŁYCZKOWSKA-HANĆKOWIAK \\ Wyższa Szkoła Bankowa w Poznaniu \\ e-mail: anna.lyczkowska-hanckowiak@wsb.poznan.pl
}

DOI: $10.15290 /$ ose.2017.03.87.09

\title{
BEHAWIORALNA WARTOŚĆ BIEŻĄCA W POSTACI SKIEROWANYCH LICZB ROZMYTYCH
}

\begin{abstract}
Streszczenie
Punktem wyjścia tych rozważań jest behawioralna wartość bieżąca (BPV) zdefiniowana jako dodatnia L-R liczba rozmyta. W tej pracy informacje opisane za pomocą BPV zostały uzupełnione o subiektywna prognozę zwrotu trendu ceny rynkowej. Prognozę tę zaimplementowano w modelu BPV jako zwrot dodatniej liczby rozmytej. Posłużono się tutaj poniższymi zasadami zapisu domniemanego zwrotu trendu.

1. Domniemanie wzrostu wartości ceny zapisujemy za pomocą dodatniej orientacji liczby rozmytej.

2. Domniemanie spadku wartości ceny zapisujemy za pomocą ujemnej orientacji liczby rozmytej.

W ten sposób BPV została przedstawiona jako rozmyta liczba skierowana. Tak określoną BPV zastosowano do wyznaczenia stopy zwrotu. Przy oczywistym założeniu, że wartość przyszła jest zmienną losowa, wyznaczona stopa zwrotu została opisana jako skierowany, rozmyty zbiór probabilistyczny. Na koniec dowiedziono, że stopa zwrotu wykazuje zwrot przeciwny do zwrotu BPV, co jest zgodne z teorią finansów.
\end{abstract}

Słowa kluczowe: behawioralne finanse, wartość bieżąca, skierowana liczba rozmyta

\section{BEHAVIOURAL PRESENT VALUE IN TERMS OF ORDERED FUZZY NUMBERS}

\section{Summary}

The starting point for our discussion is behavioural present value defined as a positive L-R fuzzy number. In this paper, the information described by means of BPV is supplemented with a subjective forecast of the orientation of the market price trend. The forecast is implemented in the BPV model as an orientation of the positive fuzzy number. The following rules of recording the alleged orientation of the trend are used:

1. Presumption of market price increase is described as positive orientation of fuzzy number.

2. Presumption of market price decrease is described as negative orientation of fuzzy number.

In this way, BPV is presented as an ordered fuzzy number. Thus defined BPV is used to determine the rate of return. With the obvious assumption that the future value is a random variable, the determined rate of return is described as an ordered fuzzy probabilistic set. Finally, it is shown that the return rate reveals an orientation opposite to the orientation of $\mathrm{BPV}$, which is consistent with the theory of finance.

Key words: behavioural finance, present value, ordered fuzzy number

JEL: C44, C02, G10 


\section{Wstęp}

Przez wartość bieżącą (w skrócie PV) rozumie się wartość teraźniejszego ekwiwalentu płatności dostępnej w ustalonym momencie [Piasecki, 2011a]. Powszechnie jest już akceptowany pogląd, że PV przyszłych przepływów finansowych może być wartością przybliżona. Z tego powodu PV jest przedstawiona jako liczba rozmyta. Początków takiego opisu PV należy szukać w pracach Warda [1985] i Buckleya [1987]. Klasyczna aksjomatyczna definicja PV Peccatiego [1972] została uogólniona do przypadku rozmytego przez Calziego [1990], który ukazał PV jako przedział rozmyty. Na przestrzeni ostatnich lat teorię tę w istotny sposób pogłębili i rozszerzyli m.in.: Greenhut i inni [1995], Sheen [2005], Gutierrez [1989], Kuchta [2000], Lesage [2001].

W pracach [Piasecki, 2011a; 2011b; Piasecki, Siwek, 2014] behawioralną wartość bieżąca (w skrócie BPV) zdefiniowano jako nieprecyzyjnie oszacowaną PV, oceniona z uwzględnieniem wpływu czynników behawioralnych na podstawie ceny rynkowej instrumentu finansowego.

Celem prezentowanej pracy jest poszerzenie zbioru informacji opisywanych za pomocą BPV o subiektywna prognozę orientacji trendu ceny rynkowej.

\section{Skierowane liczby rozmyte}

Zbiory i liczby rozmyte pozwalają formalnie opisywać oraz przetwarzać wielkości $\mathrm{i}$ informacje nieprecyzyjne. Zbiór rozmyty $A$ w danej przestrzeni $\mathbb{X}$ definiuje się jako zbiór par $A=\left\{\left(x, \mu_{A}\right): x \in \mathbb{X}\right\}$, gdzie $\mu_{A}: \mathbb{X} \rightarrow[0 ; 1]$ jest funkcja, która każdemu elementowi $x \in \mathbb{X}$ przypisuje jego stopień przynależności do zbioru $A$. Liczba rozmyta (w skrócie $\mathrm{FN}$ ) to podzbiór rozmyty $S$ określony na przestrzeni liczb rzeczywistych $\mathbb{R}$ przez swoją półciagłą z góry funkcję przynależności $\mu_{S}: \mathbb{R} \rightarrow[0 ; 1]$ spełniającą warunki [Dubois, Prade, 1979]:

$$
\begin{aligned}
& \text { - } \quad \exists_{x \in \mathbb{R}}: \mu_{S}(x)=1, \\
& \text { - } \quad \forall_{x, y, z \in \mathbb{R}}: x \leq y \leq z \Rightarrow \mu_{S}(y) \geq \min \left(\mu_{S}(x), \mu_{S}(z)\right) .
\end{aligned}
$$

Wzorując się na pracy [Dubois, Prade, 1980], dla każdej czwórki $\left(a_{S}, b_{S}, c_{S}, d_{S}\right) \in \mathbb{R}^{4}$ spełniajacej warunek $a_{S} \leq b_{S} \leq c_{S} \leq d_{S}$ definiujemy szczególny rodzaj FN $S\left(a_{S}, b_{S}, c_{S}, d_{S}\right)$ typu LR (w skrócie LR-FN). Każda z LR-FN $S\left(a_{S}, b_{S}, c_{S}, d_{S}\right)$ jest reprezentowana przez swoją funkcję przynależności $\mu_{S}: \mathbb{R} \rightarrow[0 ; 1]$ określoną następująco:

$$
\mu_{S}(x)= \begin{cases}0, & x \in]-\infty ; a_{S}[ \\ L_{S}(x), & x \in\left[a_{S} ; b_{S}[\right. \\ 1, & x \in\left[b_{S} ; c_{S}\right] \\ R_{S}(x), & \left.x \in] c_{S} ; d_{S}\right] \\ 0, & x \in] d_{S} ; \infty[\end{cases}
$$


gdzie lewa funkcja odniesienia $L_{S}:\left[a_{S} ; b_{S}\right] \rightarrow[0 ; 1]$ jest prawostronnie ciagła funkcja rosnąca i prawa funkcja odniesienia $R_{S}:\left[c_{S}, d_{S}\right] \rightarrow[0 ; 1]$ jest lewostronnie ciagłą funkcją malejąca. Dowolną parę funkcji $\left(L_{S}, R_{S}\right)$ nazywamy parą funkcji odniesienia. Dla pary funkcji odniesienia $\left(L_{S}, R_{S}\right)$ wyznaczamy parę ich uogólnionych odwrotności $\left(L_{S}^{*} ; R_{S}^{*}\right)$ określonych następująco:

$$
\begin{aligned}
& L_{S}^{\star}(\alpha)=\min \left\{x \in\left[a_{S} ; b_{S}\right]: L_{S}(x) \geq \alpha\right\}, \\
& R_{S}^{*}(\alpha)=\max \left\{x \in\left[c_{S} ; d_{S}\right]: R_{S}(x) \geq \alpha\right\} .
\end{aligned}
$$

Uogólniona odwrotność $L_{S}^{*}:[0 ; 1] \rightarrow\left[a_{S} ; b_{S}\right]$ lewej funkcji odniesienia jest ciagła funkcją niemalejąca. Uogólniona odwrotność $R_{S}^{*}:[0 ; 1] \rightarrow\left[c_{s} ; d_{s}\right]$ prawej funkcji odniesienia jest ciagłą funkcją nierosnąca.

W pracy [Dubois, Prade, 1980] LR-FN zdefiniowano jedynie dla przypadku czwórki $\left(a_{S}, b_{S}, c_{S}, d_{S}\right) \in \mathbb{R}^{4}$ spełniającej warunek $a_{S}<b_{S} \leq c_{S}<d_{S}$ oraz ciagłych funkcji odniesienia będących suriekcjami.

Skierowane liczby rozmyte (w skrócie OFN) zostały wprowadzone przez Kosińskiego i współautorów w serii artykułów [Kosiński, Prokopowicz, Ślęzak, 2002 a, b; 2003; Kosiński, 2006] jako rozszerzenie FN. Pojęcie to wdrożono tam w sposób intuicyjny za pomocą wykresów. Tutaj uściślimy je w zakresie niezbędnym do realizacji celu poznawczego postawionego na wstępie ${ }^{1}$. Pojęcie OFN jest ściśle powiązane z uporządkowana para $\left(f_{S}, g_{S}\right)$ słabo monotonicznych ciagłych suriekcji $f_{S}:[0 ; 1] \rightarrow U P_{S}$ i $g_{S}:[0 ; 1] \rightarrow D O W N_{S}$ spełniających warunki:

$$
\begin{gathered}
\left(f_{s}(1)-f_{s}(0)\right) \cdot\left(g_{s}(1)-g_{s}(0)\right) \leq 0, \\
\left|f_{s}(1)-g_{s}(1)\right| \leq\left|f_{s}(0)-g_{s}(0)\right|, \\
U P_{S} \cap D O W N_{S}=\left\{f_{s}(1)\right\} \cap\left\{g_{s}(1)\right\} .
\end{gathered}
$$

Funkcja $f_{S}:[0 ; 1] \rightarrow U P_{S}$ jest nazywana funkcją wznosząca, zaś funkcja $g_{S}:[0 ; 1] \rightarrow D O W N_{S}$ jest nazywana funkcją opadająca. Obie te funkcje mają swoja wspólną nazwę - funkcje Kosińskiego. Warunki: (6), (7) i (8) implikują że każda para Kosińskiego spełnia dokładnie jeden z poniższych warunków:

$$
\begin{aligned}
& f_{S}(0) \leq f_{S}(1) \leq g_{S}(1) \leq g_{S}(0), \\
& f_{S}(0) \geq f_{S}(1) \geq g_{S}(1) \geq g_{S}(0) .
\end{aligned}
$$

W przypadku spełnienia warunku (9) funkcję $f_{S}$ nazywamy początkową funkcja Kosińskiego, natomiast funkcję $g_{S}$ końcową funkcją Kosińskiego. Jeśli jest spełniony warunek (10), to funkcję $f_{S}$ końcową funkcją Kosińskiego, zaś funkcję $g_{S}$ początkowa funkcją Kosińskiego.

Korzystając z tych określeń, dla dowolnej pary Kosińskiego $\left(f_{S}, g_{S}\right)$ definiujemy OFN $\overleftrightarrow{S}$ jako parę $\langle S, \mho\rangle$ złożoną z LR-FN $S \in \mathcal{F}(\mathbb{R})$ i orientacji $\mho$, gdzie:

${ }^{1}$ Całość omówienia pojęcia OFN opracowano na podstawie: [Piasecki, 2017]. 
- $\quad$ uogólniona odwrotność $L_{S}^{*}$ lewej funkcji odniesienia jest równa początkowej funkcji Kosińskiego;

- $\quad$ uogólniona odwrotność $R_{S}^{*}$ prawej funkcji odniesienia jest równa końcowej funkcji Kosińskiego;

- $\quad$ orientacja $\mho$ jest określona jako wspólny zwrot wszystkich wektorów prowadzących z przeciwdziedziny $U P_{S}$ funkcji wznoszącej do przeciwdziedziny $D O W N_{S}$ funkcji opadającej.

Powyższa definicja w pełni odpowiada intuicyjnemu określeniu OFN sformułowanemu przez Kosińskiego.

Ciąłłość funkcji Kosińskiego powoduje, że $U P_{S}$ i $D O W N_{S}$ są przedziałami domkniętymi. Liczby $f_{S}(0)$ i $f_{S}(1)$ sa granicami przedziału $U P_{S}$. Liczby $g_{S}(0)$ i $g_{S}(1)$ sa granicami przedziału $D O W N_{S}$. Z tego powodu dowolną OFN $\overleftrightarrow{S}_{z}$ danymi $U P_{S}$ i $D O W N_{S}$ oznaczamy za pomocą symbolu $\overleftrightarrow{S}\left(f_{S}(0), f_{S}(1), g_{S}(1), g_{S}(0)\right)$.

Kiedy $f_{S}(0)<g_{s}(0)$, to wtedy warunek (9) opisuje dodatnią orientację OFN. W tym przypadku funkcja wznosząca $f_{S}$ jest niemalejąca i funkcja opadająca $g_{S}$ jest nierosnąca. Z zależności: (3), (4) i (5) wynika, że dodatnio zorientowana OFN $\overleftrightarrow{S}\left(f_{S}(0), f_{S}(1), g_{S}(1), g_{S}(0)\right)$ jednoznacznie wyznacza FN $S\left(f_{S}(0), f_{S}(1), g_{S}(1)\right.$ $\left.g_{S}(0)\right)$ opisaną przez swą funkcję przynależności $\mu_{S}: \mathbb{R} \rightarrow[0 ; 1]$ daną następująco:

gdzie:

$$
\mu_{S}(x)=\left\{\begin{array}{cc}
0, & x \in]-\infty ; f_{S}(0)[ \\
f_{S}^{\triangleleft}(x), & x \in\left[f_{S}(0) ; f_{S}(1)[\right. \\
1, & x \in\left[f_{S}(1) ; g_{S}(1)\right], \\
g_{S}^{\triangleright}(x), & \left.x \in] g_{S}(1) ; g_{S}(0)\right] \\
0, & x \in] g_{S}(0) ; \infty[
\end{array}\right.
$$

$$
\begin{aligned}
& f_{S}^{\triangleleft}(x)=\max \left\{\alpha \in[0 ; 1]: f_{S}(\alpha)=x\right\}, \\
& g_{S}^{\triangleright}(x)=\min \left\{\alpha \in[0 ; 1]: g_{S}(\alpha)=x\right\} .
\end{aligned}
$$

Na rysunku 1. przedstawiono dodatnio zorientowaną skierowaną liczbę rozmytą (orientację zaznaczono strzałką). 
RYSUNEK 1.

Dodatnia orientacja OFN $\overleftrightarrow{S}=\left(f_{S}(0), f_{S}(1), g_{S}(1), g_{S}(0)\right)$

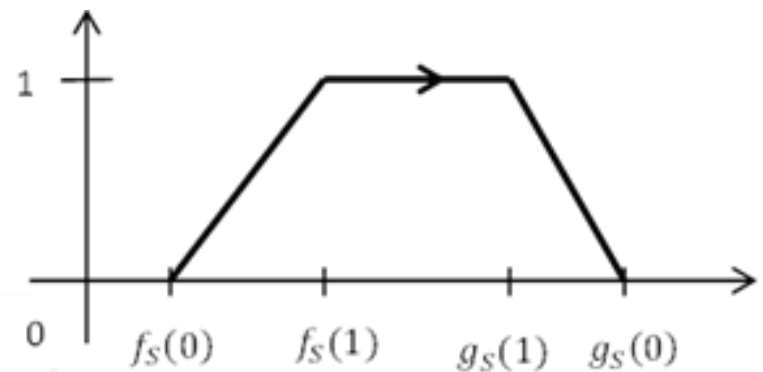

Źródło: opracowanie własne.

Kiedy $f_{S}(0)>g_{S}(0)$, to wtedy warunek (10) opisuje ujemną orientację OFN. W tym przypadku funkcja wznoszaca $f_{S}$ jest nierosnąca i funkcja opadająca $g_{S}$ jest niemalejąca. Z zależności: (3), (4) i (5) wynika, że ujemnie zorientowana OFN $\overleftrightarrow{S}\left(f_{S}(0), f_{S}(1), g_{S}(1), g_{S}(0)\right)$ jednoznacznie determinuje FN $S\left(g_{S}(0), g_{S}(1), f_{S}(1)\right.$ $\left.f_{S}(1), f_{S}(0)\right)$ opisana przez swą funkcję przynależności $\mu_{S}: \mathbb{R} \rightarrow[0 ; 1]$ daną następująco:

gdzie:

$$
\mu_{S}(x)=\left\{\begin{array}{cc}
0, & x \in-\infty ; g_{S}(0)[ \\
g_{S}^{\triangleleft}(x), & x \in\left[g_{S}(0) ; g(1)[\right. \\
1, & x \in\left[g_{S}(1) ; f_{S}(1)\right] \\
f_{S}^{\triangleright}(x), & \left.x \in] f_{S}(1) ; f_{S}(0)\right] \\
0, & x \in] f_{S}(0) ; \infty[
\end{array},\right.
$$

$$
\begin{gathered}
g_{S}^{\triangleleft}(x)=\max \left\{\alpha \in[0 ; 1]: g_{S}(\alpha)=x\right\}, \\
f_{S}^{\triangleright}(x)=\min \left\{\alpha \in[0 ; 1]: f_{S}(\alpha)=x\right\} .
\end{gathered}
$$

$\mathrm{Na}$ rysunku 2. przedstawiono ujemnie zorientowaną skierowaną liczbę rozmytą (orientację zaznaczono strzałka).

Skierowana liczba rozmyta $\overleftrightarrow{S}=\left(f_{S}(0), f_{S}(1), g_{S}(1), g_{S}(0)\right)$ jest dodatnia, jeżeli spełnia warunek:

$$
\min \left\{f_{S}(0), g_{S}(0)\right\}>0 .
$$

Na koniec zauważmy, że w przypadku $f_{S}(0)=g_{S}(0)$ orientacja OFN jest niezdefiniowana. Wtedy jednak rozpatrujemy liczbę $\overleftrightarrow{S}\left(f_{S}(0), f_{S}(0), f_{S}(0), f_{S}(0)\right)$ jako ze swej natury niezorientowaną liczbę rzeczywistą $f_{S}(0) \in \mathbb{R}$. 
RYSUNEK 2.

$$
\text { Ujemna orientacja OFN } \overleftrightarrow{S}=\left(f_{S}(\mathbf{0}), f_{S}(\mathbf{1}), g_{S}(\mathbf{1}), g_{S}(\mathbf{0})\right)
$$

Źródło: opracowanie własne.

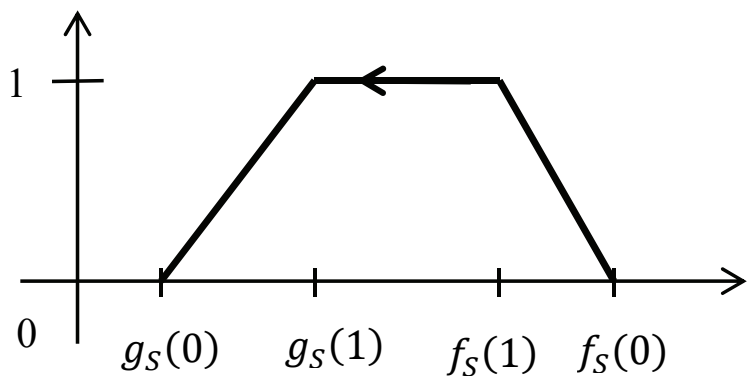

Operacje na liczbach rozmytych zostały zdefiniowane przez Kosińskiego [Kosiński, 2006] jako rozszerzenie operacji określonych na przestrzeni $\mathbb{R}$. W szczególnym przypadku dla dowolnej dodatniej liczby rzeczywistej $a \in \mathbb{R}^{+}$i dla dodatniej OFN $\overleftrightarrow{A}$ mamy określone:

- dzielenie skalarne:

$$
\overleftrightarrow{B}=a \oslash \overleftrightarrow{A}
$$

gdzie:

$$
\forall_{x \in[0,1]}: f_{B}(x)=a / f_{A}(x) \wedge g_{B}(x)=a / g_{A}(x),
$$

- odejmowanie skalarne:

$$
\overleftrightarrow{C}=\overleftrightarrow{A} \ominus a
$$

gdzie:

$$
\forall_{x \in[0,1]}: f_{C}(x)=f_{A}(x)-a \wedge g_{C}(x)=g_{A}(x)-a .
$$

\section{Skierowana behawioralna wartość bieżąca}

Rozważmy dowolny instrument finansowy będący przedmiotem obrotu na silnie efektywnym rynku finansowym. Cena rynkowa $\check{C}$ tego instrumentu finansowego może zmieniać się w czasie, dlatego możemy mówić o trendzie ceny rynkowej. Finansowa równowaga jest stanem rynku finansowego, w którym trend ceny rynkowej jest stały. Wtedy wartość ceny rynkowej $\breve{C}$ jest równa cenie równowagi $C_{0}$ określonej przez analizę techniczną lub fundamentalna.

W pracy Piaseckiego [2016] PV dowolnego przepływu finansowego została przedstawiona jako użyteczność tegoż przepływu. Wartość bieżąca dowolnego przepływu finansowego zależy zarówno od przesłanek obiektywnych, jak i subiektywnych. Na silnie 
efektywnym rynku finansowym każdy z inwestorów ustala tę samą wartość $C_{0}$, która w tej sytuacji ma charakter obiektywny. Równocześnie wszyscy uczestnicy rynku obserwują obiektywną wartość $\breve{C}$ ceny rynkowej. Rozważmy dowolną PV ocenioną pod wpływem m.in. przesłanek behawioralnych. Stany środowiska behawioralnego są zdefiniowane nieprecyzyjnie, zatem odchylenie wyznaczonej PV od ceny rynkowej musi być nieprecyzyjne. Każda behawioralna ocena jest subiektywna. W tej sytuacji ocena PV ma subiektywny charakter i zazwyczaj jest wieloznaczna. Każda z rozważanych alternatyw tej wyceny nazywa się potencjalną PV (w skrócie PPV). Behawioralną wartościa bieżąca (w skrócie BPV) jest zbiór wszystkich PPV. Uzależnienie PV od subiektywnych czynników finansowych powoduje, że każdy z inwestorów może wyznaczyć własna wersję BPV. Stąd wszystkie dalsze rozważania są prowadzone dla ustalonego inwestora. W przypadku równowagi finansowej, kiedy to cena rynkowa $\breve{C}$ pokrywa się z cena równowagi $C_{0}$, to jest $\check{C}=C_{0}$, inwestor musi uwzględniać możliwość spadków i wzrostów notowań (podatność inwestora na wpływ wewnętrznych i zewnętrznych impulsów behawioralnych). W tej sytuacji zakres zmienności PPV spełnia warunek $C_{\min }<C_{0}<$ $C_{\max }$, gdzie:

- $\quad C_{\min }$ dolny zakres PPV zakładany w warunkach równowagi finansowej;

- $C_{\text {max }}$ górny zakres PPV zakładany w warunkach równowagi finansowej.

Przedział liczbowy $\left[C_{\min } ; C_{\max }\right]$ jest obrazem BPV dla przypadku równowagi finansowej.

W przypadku, kiedy jest notowana dowolna cena rynkowa $\check{C}$, BPV jest zależna od odchylenia $\Delta C=\check{C}-C_{0}$ ceny rynkowej od ceny równowagi. Każdy z inwestorów określa wtedy następujące wartości:

- $\check{C}_{\text {min }}$ dolny zakres PPV zakładany dla ceny rynkowej $\check{C}$;

- $\check{C}_{\text {max }}$ górny zakres PPV zakładany dla ceny rynkowej $\check{C}$.

Przedziałowy obraz BPV jednakowo traktuje wszystkie dopuszczalne wartości PPV i opisuje złożoność wpływów behawioralnych w niewystarczający sposób, ponieważ możemy przypuszczać, że inwestor w większym stopniu akceptuje PPV bardziej podobne do ceny rynkowej. Spowodowało to konieczność zbudowania modelu BPV uwzględniającego zmienność wagi poszczególnych PPV, co doprowadziło do zbudowania rozmytego obrazu BPV. Behawioralna wartość bieżąca została przedstawiona jako liczba rozmyta [Piasecki, 2016], której funkcja przynależności BPV dana jest wzorami:

- $\quad$ dla $\Delta C>0$

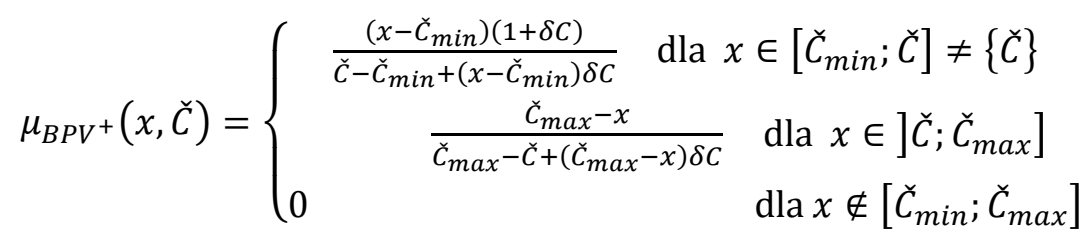


- $\quad$ dla $\Delta C \leq 0$

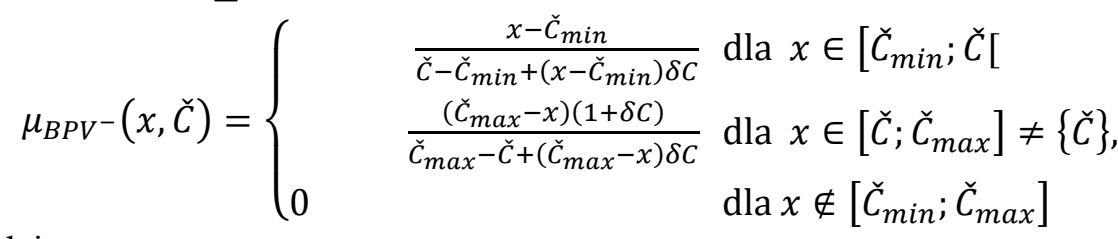

gdzie:

$\check{C}$ - obserwowana cena rynkowa,

$\delta C=\frac{|\Delta C|}{\check{C}}=\frac{\check{C}-C_{0}}{\check{C}}-$ względne odchylenie ceny rynkowej od ceny równowagi, $C_{0}$ - merytorycznie uzasadniona cena równowagi finansowej.

RYSUNEK 3.

Wykres funkcji przynależności BPV w przypadku, gdy a) $\Delta C>0$, b) $\Delta C<0$
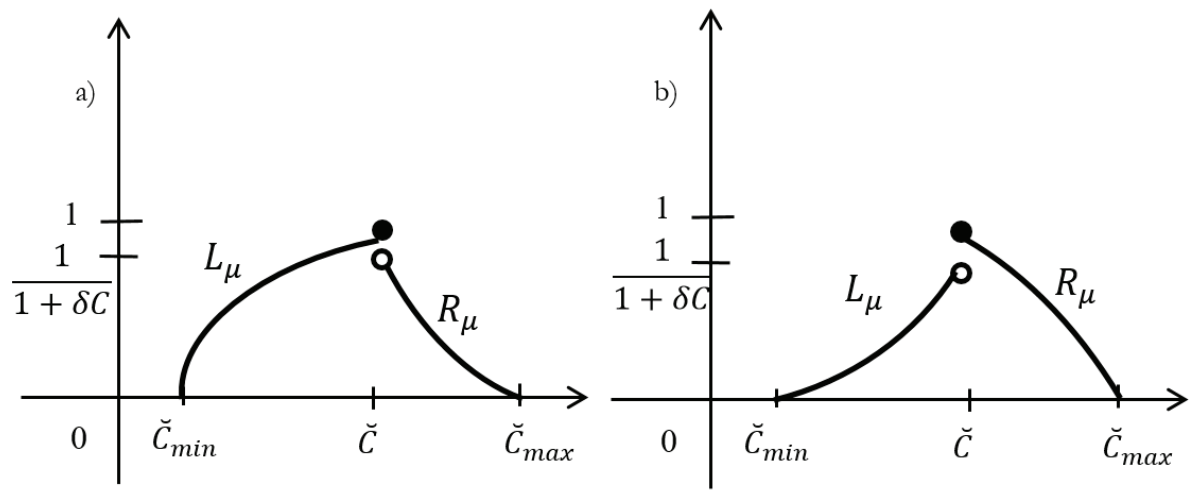

Źródło: opracowanie własne.

$\mathrm{Na}$ rysunku 3. pokazano wykres funkcji przynależności BPV w zależności od odchylenia ceny rynkowej od ceny równowagi $\Delta C$. Dla $\Delta C>0$ (rysunek 3a)) funkcja przynależności jest opisana wzorem:

$$
\mu_{B P V^{+}}(x)= \begin{cases}L_{B P V^{+}}(x) & \text { dla } x \in\left[\check{C}_{\text {min }} ; \check{C}\right] \neq\{\check{C}\}, \\ R_{B P V^{+}}(x) & \text { dla } \left.x \in] \check{C} ; \check{C}_{\text {max }}\right], \\ 0 & \text { dla } x \notin\left[\check{C}_{\text {min }} ; \check{C}_{\text {max }}\right],\end{cases}
$$

gdzie stosując oznaczenia Dubois i Prade, lewa oraz prawa funkcja odniesienia, odpowiednio $\left.\left.L_{B P V^{+}}:\left[\check{C}_{\text {min }} ; \check{C}\right] \rightarrow[0 ; 1], R_{B P V^{+}}:\right] \check{C}_{;} \check{C}_{\text {max }}\right] \rightarrow\left[0 ; \frac{1}{1+\delta}[\right.$ sa zdefiniowane jako:

$$
\begin{aligned}
& L_{B P V^{+}}(x)=\frac{\left(x-\check{C}_{\min }\right)(1+\delta C)}{\check{C}-\check{C}_{\text {min }}+\left(x-\check{C}_{\text {min }}\right) \delta C} \quad \text { dla } x \in\left[\check{C}_{\text {min }} ; \check{C}\right] \\
& R_{B P V^{+}}(x)= \begin{cases}1 & \text { dla } x=\check{C} \\
\frac{\check{C}_{\text {max }}-x}{\check{C}_{\text {max }}-\check{C}+\left(\check{C}_{\text {max }}-x\right) \delta C} & \text { dla } \left.x \in] \check{C} ; \check{C}_{\text {max }}\right]\end{cases}
\end{aligned}
$$


Dla $\Delta C<0$ (rysunek 3b)) funkcja przynależności jest natomiast opisana przez:

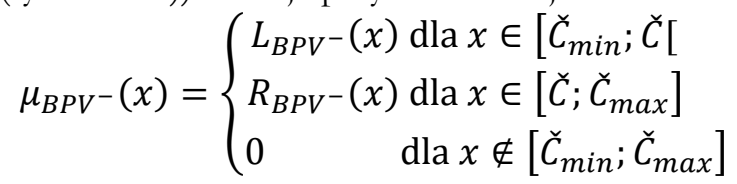

gdzie lewa i prawa funkcja odniesienia, odpowiednio: $L_{B P V^{-}}:\left[\check{C}_{\text {min }} ; \check{C}[\rightarrow\right.$ $\left[0 ; \frac{1}{1+\delta C}\left[, \quad R_{B P V^{-}}:\left[\check{C} ; \check{C}_{\max }\right] \rightarrow[0 ; 1]\right.\right.$ są określone za pomocą wzorów:

$$
\begin{aligned}
& L_{B P V^{-}}(x)= \begin{cases}\frac{x-\check{C}_{\text {min }}}{\check{C}-\check{C}_{\text {min }}+\left(x-\check{C}_{\text {min }}\right) \delta C} & \text { dla } x \in\left[\check{C}_{\text {min }} ; \check{C}[,\right. \\
1 & \text { dla } x=\check{C},\end{cases} \\
& R_{B P V^{-}}(x)=\frac{\left(\check{C}_{\max }-x\right)(1+\delta C)}{\check{C}_{\text {max }}-\check{C}+\left(\check{C}_{\text {max }}-x\right) \delta C} \quad \text { dla } x \in\left[\check{C}_{;} \check{C}_{\text {max }}\right] \text {. }
\end{aligned}
$$

Funkcje przynależności $\mu_{B P V^{+}}$i $\mu_{B P V^{-}}$są przedziałami ciagłe i monotoniczne. Dlatego w każdym z przedziałów istnieją funkcje odwrotne do $L_{B P V^{+}}, R_{B P V^{+}}, L_{B P V^{-}}$, $R_{B P V^{-}}$oraz są odpowiednio równe:

$$
\begin{aligned}
& L_{B P V^{+}}^{\triangleleft}(x)=\frac{\left(\check{C}_{\min }(1+\delta C)-\breve{C}\right) x-\check{C}_{\min }(1+\delta C)}{x \delta C-(1+\delta C)} \quad \text { dla } x \in[0 ; 1], \\
& R_{B P V^{+}}^{\triangleright}(x)=\left\{\begin{array}{cl}
\frac{\left[\check{C}_{\max }(1+\delta C)-\breve{C}\right] x-\breve{C}_{\max }}{x \delta C-1} & \text { dla } x \in\left[0 ; \frac{1}{1+\delta}\right] \\
\check{C} & \text { dla } x \in\left[\frac{1}{1+\delta} ; 1\right]
\end{array}\right. \\
& L_{B P V^{-}}^{\triangleleft}(x)=\left\{\begin{array}{cl}
\frac{\left(\check{C}_{\min }(1+\delta C)-\breve{C}\right) x-\check{C}_{\min }}{x \delta C-1} & \text { dla } x \in\left[0 ; \frac{1}{1+\delta}\right] \\
\check{C} & \text { dla } x \in\left[\frac{1}{1+\delta} ; 1\right]
\end{array}\right. \\
& R_{B P V^{-}}^{\triangleright}(x)=\frac{\left[\check{C}_{\max }(1+\delta C)-\breve{C}\right] x-\check{C}_{\max }(1+\delta C)}{x \delta C-(1+\delta C)} \quad \text { dla } x \in[0 ; 1]
\end{aligned}
$$

Dla obserwowanej ceny rynkowej $\check{C}$ behawioralną wartość bieżąca przedstawimy jako skierowaną liczbę rozmyta. Jest to uzasadnione prostotą realizacji działań arytmetycznych na przestrzeni skierowanych liczb rozmytych [Kacprzak, 2012]. Przewidywanie wzrostowego trendu ceny rynkowej będziemy zaznaczać za pomocą orientacji dodatniej, a przewidywanie spadkowego trendu ceny rynkowej za pomocą orientacji ujemnej. Rozważymy cztery przypadki w zależności od $\Delta C$ :

1. $\Delta C>0$, czyli gdy cena rynkowa przewyższa cenę równowagi $\left(\check{C}>C_{0}\right)$;

2. $\Delta C<0$, czyli gdy cena równowagi przewyższa cenę rynkowa $\left(\check{C}<C_{0}\right)$.

W każdym z powyższych przypadków uwzględnia się dwie sytuacje, kiedy:

a) spodziewamy się na podstawie własnych, subiektywnych przesłanek, że cena rynkowa wzrośnie;

b) spodziewamy się na podstawie własnych, subiektywnych przesłanek, że cena rynkowa zmaleje.

Liczbie rozmytej, która opisuje BPV, nadajemy w przypadku a) orientację dodatnia, a w przypadku b) orientację ujemna. Warto zauważyć, że orientacja dodatnia jest identyczna ze zbiorem rozmytym. 
RYSUNEK 4. Wykres funkcji przynależności BPV zorientowanej dodatnio, gdy $\Delta C>0$
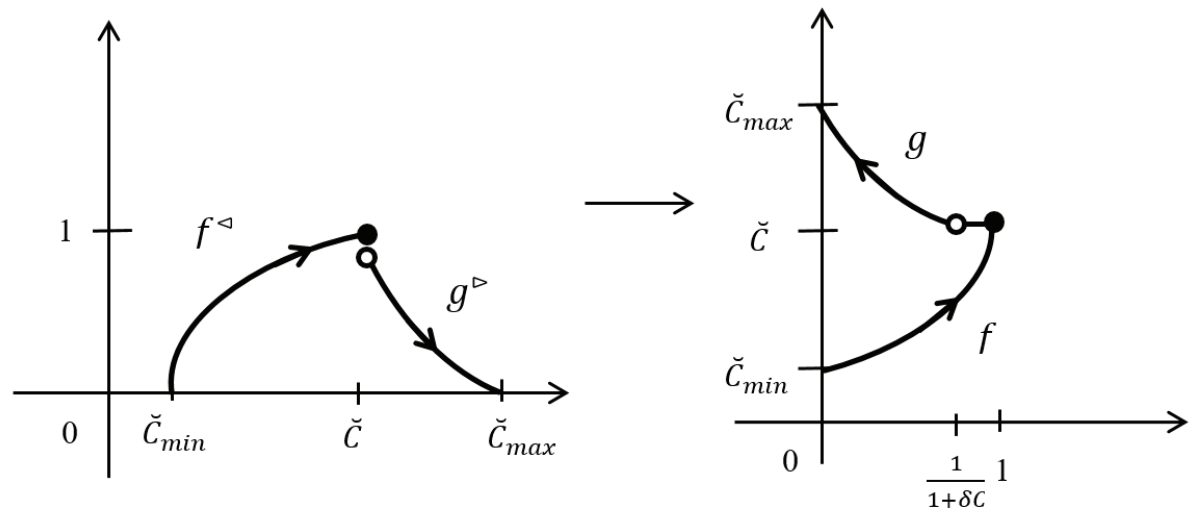

Źródło: opracowanie własne.

Rysunek 4. (przypadek 1a)) ilustruje sytuację, kiedy $\Delta C>0$, czyli gdy cena rynkowa przewyższa cenę równowagi. Wykres po lewej stronie przedstawia funkcję przynależności behawioralnej wartości bieżącej. Behawioralna wartość bieżąca jest zorientowana dodatnio, to znaczy spodziewamy się, że cena rynkowa wzrośnie. Rysunek po prawej stronie obrazuje funkcję przynależności opisującą standaryzowaną rozmytą postać BPV za pomocą skierowanej liczby rozmytej OFN jako parę funkcji Kosińskiego $\mathrm{BPV}=(f, g)$, gdzie:

$$
\begin{aligned}
& f(x)=L_{B P V^{+}}^{\triangleleft}(x), x \in[0,1], \\
& g(x)=R_{B P V^{+}}^{\triangleright}(x), x \in[0,1],
\end{aligned}
$$

$f(0)=\check{C}_{\text {min }}, f(1)=\check{C}, g(1)=\check{C}, g(0)=\check{C}_{\text {max }}$. Funkcja $f$ odpowiada części wznoszącej UP,

a funkcja $g$ - części opadającej DOWN. Na przedziale $\left[\frac{1}{1+\delta C}, 1\right]$ została dołączona funkcja stała równa $\check{C}$.

Rysunek 5. (przypadek 1b)) pokazuje stan rzeczy, kiedy $\Delta C>0$, czyli gdy cena rynkowa przewyższa cenę równowagi. Podobnie jak poprzednio, wykres po lewej stronie prezentuje funkcję przynależności behawioralnej wartości bieżącej. Behawioralna wartość bieżąca jest tutaj jednak zorientowana ujemnie, to znaczy spodziewamy się, że cena rynkowa zmaleje. Rysunek po prawej stronie przedstawia funkcję przynależności opisująca standaryzowaną rozmytą postać BPV za pomocą skierowanej liczby rozmytej OFN jako parę funkcji Kosińskiego BPV $=(g, f)$, gdzie funkcje $f$ i $g$ są dane za pomocą wzorów (7) i (8). Funkcja $g$ odpowiada tutaj części wznoszącej UP, a funkcja $f$ - części opadającej DOWN. Na przedziale $\left[\frac{1}{1+\delta C}, 1\right]$ została dołączona funkcja stała równa $\check{C}$. 
RYSUNEK 5.

Wykres funkcji przynależności BPV zorientowanej ujemnie, gdy $\Delta C>0$

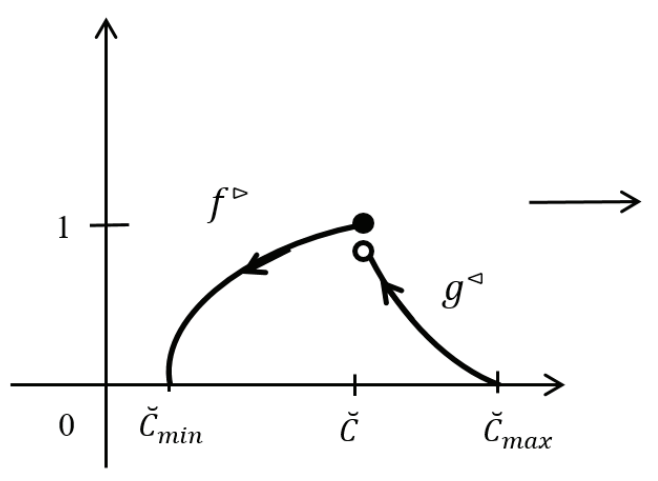

Źródło: opracowanie własne.

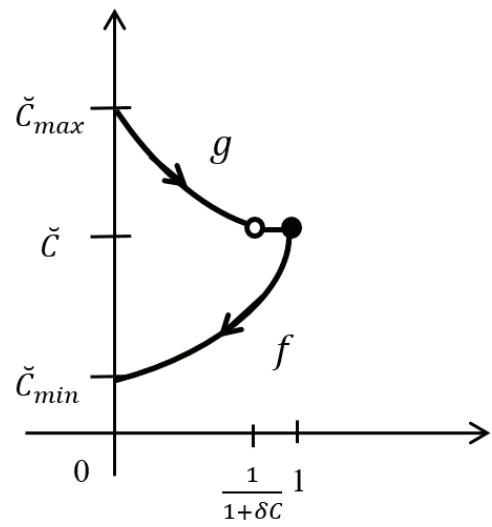

Rysunek 6. (przypadek 2a) ilustruje sytuację, kiedy $\Delta C<0$, czyli gdy cena równowagi przewyższa cenę rynkową. Analogicznie jak w przypadku 1a), wykres po lewej stronie obrazuje funkcję przynależności behawioralnej wartości bieżącej. Behawioralna wartość bieżąca jest zorientowana dodatnio, to znaczy spodziewamy się, że cena rynkowa wzrośnie. Rysunek po prawej stronie prezentuje funkcję przynależności opisującą standaryzowaną rozmyta postać BPV za pomocą skierowanej liczby rozmytej OFN jako parę funkcji Kosińskiego BPV= $(f, g)$, gdzie:

$$
\begin{aligned}
& f(x)=L_{B P V^{-}}^{\triangleright}(x), x \in[0,1], \\
& g(x)=R_{B P V^{-}}^{\triangleleft}(x), x \in[0,1],
\end{aligned}
$$

$f(0)=\check{C}_{\text {min }}, f(1)=\check{C}, g(1)=\check{C}, g(0)=\check{C}_{\text {max }}$. Funkcja $f$ odpowiada części wznoszącej UP,

a funkcja $g$ - części opadającej DOWN. Na przedziale $\left[\frac{1}{1+\delta C}, 1\right]$ została dołączona funkcja stała równa $\check{C}$. 
RYSUNEK 6. Wykres funkcji przynależności BPV zorientowanej dodatnio, gdy $\Delta C<0$
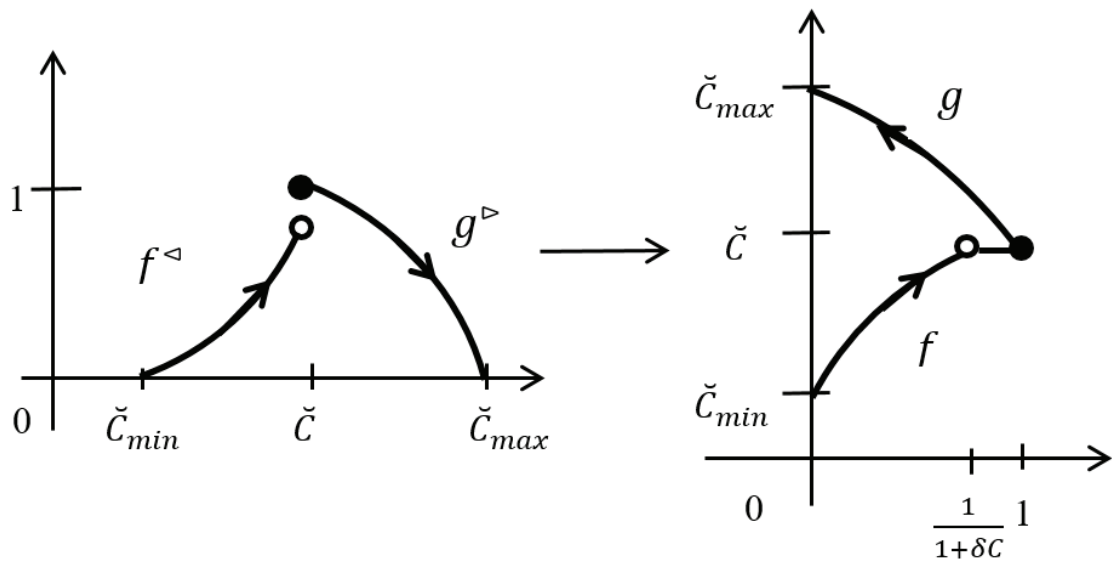

Źródło: opracowanie własne.

Rysunek 7. (przypadek 2b)) ilustruje stan, kiedy $\Delta C<0$, czyli gdy cena równowagi przewyższa cenę rynkowa. Podobnie jak w przypadku 1b), wykres po lewej stronie przedstawia funkcję przynależności behawioralnej wartości bieżącej. Behawioralna wartość bieżąca jest zorientowana ujemnie, to znaczy spodziewamy się, że cena rynkowa zmaleje. Rysunek po prawej stronie obrazuje funkcję przynależności opisującą standaryzowaną rozmyta postać BPV za pomocą skierowanej liczby rozmytej OFN jako parę funkcji Kosińskiego BPV $=(g, f)$, gdzie funkcje $f$ i $g$ są dane za pomocą wzorów: (9) i (10). Funkcja $g$ odpowiada części wznoszącej UP, a funkcja $f$ - części opadającej DOWN. Na przedziale $\left[\frac{1}{1+\delta C}, 1\right]$ została dołączona funkcja stała równa $\check{C}$.

RYSUNEK 7.

Wykres funkcji przynależności BPV zorientowanej ujemnie, gdy $\Delta C<0$
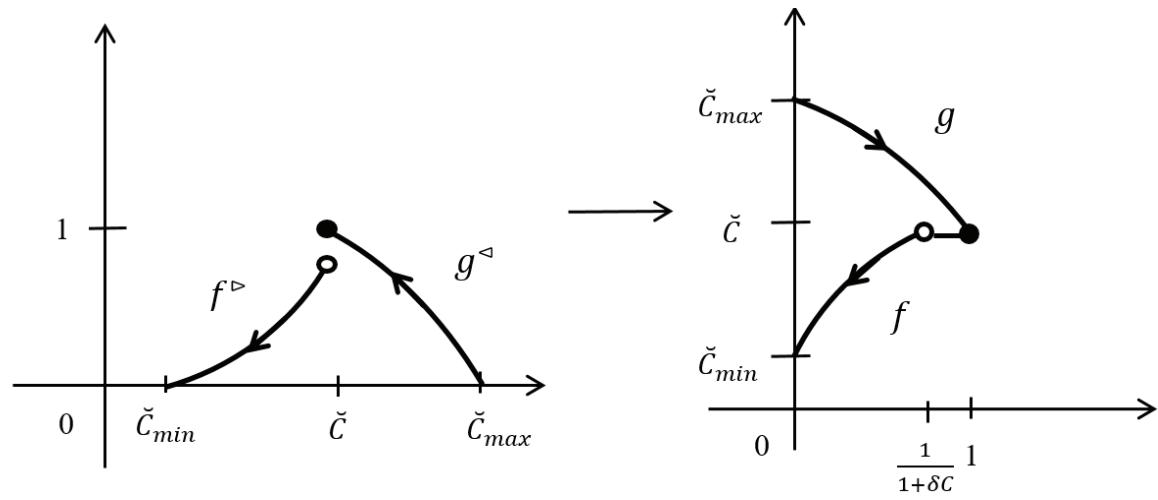

Źródło: opracowanie własne. 
Przykład 1. Dany jest instrument $A$, dla którego cena równowagi $C_{0}=110$, cena rynkowa $\check{C}=120$, odpowiednio dolny $\check{C}_{\text {min }}=108$ i gómy $\check{C}_{\max }=138$ zakres BPV przy obserwowanej cenie rynkowej. Mamy $\Delta C=\check{C}-C_{0}=120-110=10>0$, $\delta C=\frac{|10|}{120}=\frac{1}{12}$.

Funkcja przynależności opisującą standaryzowaną rozmytą postać BPV wyraża się wzorem:

czyli po uproszczeniu

$$
\mu_{B P V^{+}}(x, \breve{C})=\left\{\begin{array}{cr}
\frac{(x-108)\left(1+\frac{1}{12}\right)}{120-108+(x-108) \frac{1}{12}} & \text { dla } x \in[108,120], \\
\frac{138-x}{138-120+(138-x) \frac{1}{12}} & \text { dla } x \in] 120,138], \\
0 & \text { dla } x \notin[108,138],
\end{array}\right.
$$

$$
\mu_{B P V^{+}}(x, \check{C})=\left\{\begin{array}{lc}
\frac{13 x-1404}{x+36} & \text { dla } x \in[108,120] \\
\frac{12 x-1656}{x-354} & \text { dla } x \in] 120,138] \\
0 & \text { dla } x \notin[108,138]
\end{array},\right.
$$

Korzystając ze wzorów (7) i (8), dostajemy funkcję przynależności opisującą standaryzowana rozmyta postać BPV za pomoca dodatnio skierowanej liczby rozmytej OFN jako parę funkcji Kosińskiego BPV $=(f, g)$, gdzie:

$$
\begin{gathered}
f(x)=L_{B P V^{+}}^{-1}(x)=\frac{36 x+1404}{13-x}, x \in[0,1], \\
g(x)=\left\{\begin{array}{cc}
R_{B P V^{+}}^{-1}(x)=\frac{354 x-1656}{x-12}, & x \in\left[0, \frac{12}{13}[\right. \\
120, & x \in\left[\frac{12}{13}, 1\right]
\end{array},\right.
\end{gathered}
$$

w sytuacji, gdy spodziewamy się na podstawie własnych, subiektywnych przesłanek, że cena rynkowa wzrośnie. W sytuacji, gdy spodziewamy się na podstawie własnych, subiektywnych przesłanek, że cena rynkowa spadnie, funkcja przynależności opisująca standaryzowana rozmyta postać BPV za pomoca ujemnie skierowanej liczby rozmytej OFN jest parą funkcji Kosińskiego $\mathrm{BPV}=(g, f)$.

Skierowana rozmyta stopa zwrotu OFRR wyraża się wzorem:

$$
O F R R=\left(r_{f}, r_{g}\right)=\left(\frac{V(\omega)}{f(x)}-1, \frac{V(\omega)}{g(x)}-1\right) .
$$

W każdym z omówionych przypadków wyznaczymy OFRR. Dla sytuacji 1a) korzystając ze wzorów: (11), (7) i (8), otrzymujemy $O F R R=\left(r_{f}, r_{g}\right)$, gdzie:

$$
\begin{gathered}
r_{f}=V(\omega) \frac{x \delta C-(1+\delta C)}{\left(\check{C}_{\min }(1+\delta C)-\breve{C}\right) x-\check{C}_{\text {min }}(1+\delta C)}-1, x \in[0,1], \\
r_{g}=\left\{\begin{array}{cc}
V(\omega) \frac{x \delta C-1}{\left[\check{C}_{\max }(1+\delta C)-\breve{C}\right] x-\check{C}_{\text {max }}}-1, & x \in\left[0, \frac{1}{1+\delta C}[\right. \\
\frac{V(\omega)}{\check{C}}-1, & x \in\left[\frac{1}{1+\delta C}, 1\right] .
\end{array}\right.
\end{gathered}
$$


W przypadku 1b) OFRR $=\left(r_{g}, r_{f}\right)$, gdzie $r_{f}$ i $r_{g}$ są dane odpowiednio wzorami (12) i (13).

Dla przypadku następnego (2a)) na podstawie wzorów: (11), (9) oraz (10) dostajemy $O F R R=\left(r_{f}, r_{g}\right)$, gdzie:

$$
\begin{gathered}
r_{f}=\left\{\begin{array}{cc}
V(\omega) \frac{x \delta C-1}{\left(\check{C}_{\min }(1+\delta C)-\breve{C}\right) x-\check{C}_{\min }}-1, & x \in\left[0, \frac{1}{1+\delta C}[\right. \\
\frac{V(\omega)}{\check{C}}-1, & x \in\left[\frac{1}{1+\delta C}, 1\right]
\end{array},\right. \\
r_{g}=V(\omega) \frac{x \delta C-(1+\delta C)}{\left[\check{C}_{\max }(1+\delta C)-\check{C}\right] x-\check{C}_{\max }(1+\delta C)}-1, x \in[0,1] .
\end{gathered}
$$

W sytuacji 2b) skierowana rozmyta stopa zwrotu $O F R R=\left(r_{g}, r_{f}\right)$, gdzie $r_{f}$ i $r_{g}$ sa dane odpowiednio za pomocą wzorów (14) i (15).

Dla rozmytej behawioralnej wartości bieżącej BPV zorientowanej dodatnio skierowana rozmyta stopa zwrotu OFRR jest zorientowana ujemnie. Podobnie dla behawioralnej wartości bieżącej BPV zorientowanej ujemnie, skierowana rozmyta stopa zwrotu jest zorientowana dodatnio. Oznacza to, że przypuszczenie o wzroście ceny rynkowej pociaga za soba przypuszczenie o spadku stopy zwrotu. Analogicznie, przypuszczenie o spadku ceny rynkowej implikuje przypuszczenie o wzroście stopy zwrotu. Jest to zgodne z ogólną teorią finansów. Stopa zwrotu zachowuje zasady zapisu domniemanego zwrotu trendu. Stanowi to przyczynek do stwierdzenia, że zastosowanie skierowanych liczb rozmytych może być przydatne w finansach.

Przykład 2. Dla instrumentu opisanego w przykładzie 1. skierowana rozmyta stopa zwrotu na mocy wzorów (12) i (13) jest równa $O F R R=\left(r_{f}, r_{g}\right)$ w przypadku, gdy spodziewamy się, że cena rynkowa wzrośnie i $O F R R=\left(r_{g}, r_{f}\right)$, gdy spodziewamy się, że cena rynkowa spadnie, gdzie:

$$
\begin{gathered}
r_{f}=V(\omega) \frac{13-x}{36 x+1404}-1, x \in[0,1], \\
r_{g}=\left\{\begin{array}{ll}
V(\omega) \frac{x-12}{354 x-1656}-1, & x \in\left[0, \frac{12}{13}[\right. \\
\frac{V(\omega)}{120}-1, & x \in\left[\frac{12}{13}, 1\right]
\end{array} .\right.
\end{gathered}
$$

\section{Podsumowanie}

Behawioralna wartość bieżąca została przedstawiona za pomocą skierowanych liczb rozmytych. Liczbie rozmytej, która opisuje BPV, nadano orientację dodatnią w przypadku, gdy spodziewano się na podstawie własnych, subiektywnych przesłanek, że cena rynkowa wzrośnie, natomiast w sytuacji, kiedy spodziewano się na podstawie subiektywnych przesłanek, że cena rynkowa zmaleje - orientację ujemna. Przy oczywistym założeniu, że wartość przyszła jest zmienną losowa, wyznaczona stopa zwrotu została opisana jako skierowany rozmyty zbiór probabilistyczny. Nieprecyzyjność, przedstawiono 
tutaj przez rozmycie, nie zastapiła (nie była substytutem) losowości, ale była uzupełnieniem. Stopa zwrotu stała się stochastyczną stopa zwrotu.

Model skierowanej behawioralnej wartości bieżącej może być dobrym narzędziem w analizie i modelowaniu ekonomicznym. Wartością dodaną opisanego modelu jest możliwość uwzględnienia subiektywnych przewidywań zwrotu dalszego trendu ceny. Pozwala to przypuszczać, że uzyskane wyniki będzie można wykorzystać do analizy portfelowej. W kolejnej pracy autorka skupi się na wyznaczeniu oczekiwanej skierowanej rozmytej stopy zwrotu i ocenie ryzyka obarczającego tę stopę.

\section{Literatura}

Buckley I. J., 1987, The furzy mathematics of finance, "Fuzzy Sets and Systems", vol. 21. Calzzi M. L., 1990, Towards a general setting for the fuzzy mathematics of finance, "Fuzzy Sets and Systems", vol. 35.

Dubois D., Prade H., 1978, Operation on furzy numbers, "Int. J. System Science”, vol. 9.

Dubois D., Prade H., 1979, Fuгzy real algebra: some results, "Fuzzy Sets and Systems", vol. 2.

Dubois D., Prade H., 1980, Furzy set and systems: theory and applications, Academic Press, New York.

Greenhut J. G., Norman G., Temponi C. T., 1995, Towards a fuz:y theory of oligopolistic competition, IEEE Proceedings of ISUMA-NAFIPS, Washington.

Gutierrez I., 1989, Fuz:y numbers and Net Present V alue, "Scandinavian Journal of Management", vol. 5 , iss. 2.

Klir G. J., 1993, Developments in uncertainty-based information, Advances in Computers 36, Academic Press, San Diego.

Kacprzak D., 2010, Skierowane liczby rozmyte w modelowanin ekonomicznym, „Optimum. Studia Ekonomiczne", nr 3.

Kacprzak D., 2012, Zastosowanie skierowanych licz̧b rozmytych do prezentacji akcji, „Optimum. Studia Ekonomiczne", nr 6.

Kosiński W., Prokopowicz P., Ślęzak D., 2002, Fuz:synumbers with algebraic operations: algorithmic approach, [in:] Advances in Soft Computing, Proc. of the Sixth Int. Conference on Neutral Networks and Soft Computing, Zakopane, Poland June 11-15.

Kosiński W., Prokopowicz P., Ślęzak D., 2003, Ordered fuгży numbers, "Bulletin of the Polish Academy of Sciences", vol. 51, no 3.

Kosiński W., 2006, On fuz:ynumer calculus, "International Journal of Applied Mathematics and Computer Science", vol. 16.

Kuchta D., 2000, Fur:y capital budgeting, "Fuzzy Set and Systems", vol. 111.

Lesage C., 2001, Discounted cash-flows analysis. An interactive furzy arithmrtic approach, „European Journal of Economic and Social System", vol. 15, no 2.

Peccati L., 1972, Su di una caratterizzazione del principio del criterio dell'attualizzazione, Studium Parmense, Parma.

Piasecki K., 2011a, Behavioral Present V alue, "SSRN Electronic Journal” 1, DOI: 10.2139/ ssrn.1729351. 
Piasecki K., 2011b, Rozmyte zbiory probabilistyczne, jako narz̨dzie finansów behawioralnych, Wydawnictwo Uniwersytetu Ekonomicznego w Poznaniu, Poznań, DOI: 10.13140/ 2.1.2506.6567.

Piasecki K., 2014, Behawioralna wartość bieżqca - nowe podejście, „Optimum. Studia Ekonomiczne", nr 1 (67).

Piasecki K., 2016, Intuicyjne zbiory rozmyte jako narzedzie finansów behawioralnych, Wydawnictwo edu-Libri, Kraków-Legionowo.

Piasecki K., Siwek J., 2015, Behavioural Present V alue Defined as Fuz氵y Number - a New Approach, "Folia Oeconomica Stetinensia", vol. 15, iss. 2.

Sheen J. N., 2005, Furzy financial profitability analyses of demand side management alternatives from participant perspective, "Information Sciences", vol. 169.

Stirling W. C., 2003, Satisficing Games and Decision Making, Cambridge University Press, Cambridge.

Ward T. L., 1985, Discounted fuzzy cash flow analysis, Fall Industrial Engineering Conference Preceedings, Warszawa.

Zadeh L., 1965, Fuzæy sets, "Information and Control", vol. 8. 